\title{
'Service as Theatre: The Customer Service Behaviour of Librarians in a Market Driven World'
}

\author{
by
}

\section{Jane Cherry}

Submitted to the School of Information Management, Victoria University of Wellington in partial fulfilment of the requirements for the degree of Master of Library and Information Studies 


\section{Acknowledgements}

There are a number of people to thank for their contributions to this research. Firstly I would like to thank my supervisor, Philip Calvert. Philip took an interest in my work and gave me thought provoking and useful feedback. Thank you to the focus group participants. The focus groups were great fun and I really appreciated the frank and open contributions made by all those involved. I would also like to thank my MLIS classmates and other MLIS teaching staff, especially Chrysanna Beazley. Chrysanna helped me navigate through the ups and downs of my project.

I want to acknowledge my work colleagues at Te Aka Matua Library and Information Centre, Te Papa for their support and last but not least I'd like to thank my immediate family and large extended family - who I know are looking forward to welcoming me back so they can finally talk to me at family occasions, and once again eat my baking. And lastly, Lynda Robinson for giving me a filing cabinet. I hate to think how my research would have turned out if I had continued using boxes. 


\section{Contents}

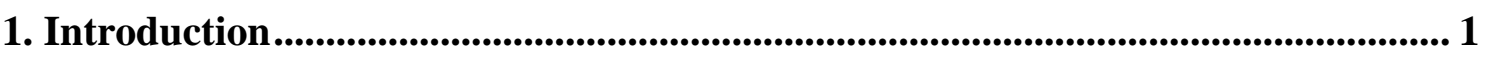

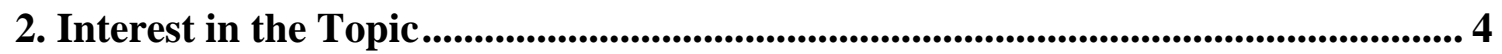

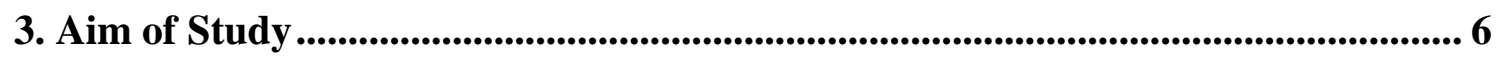

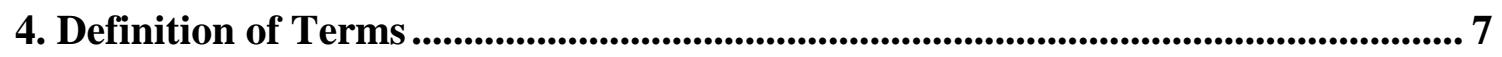

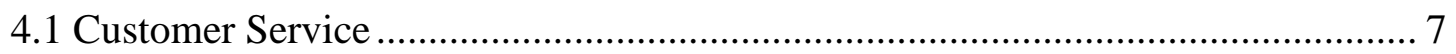

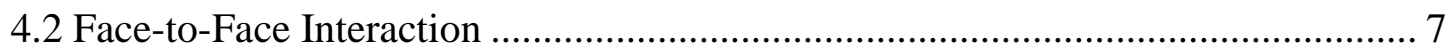

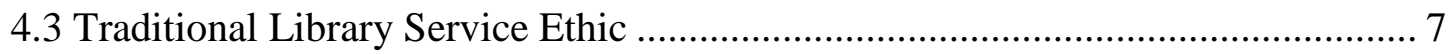

4.4 The Market-Led Approach to Customer Service .................................................. 8

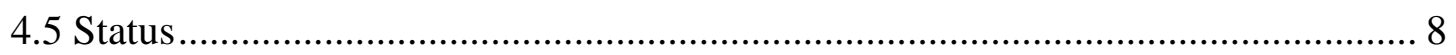

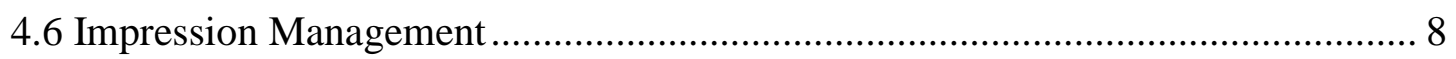

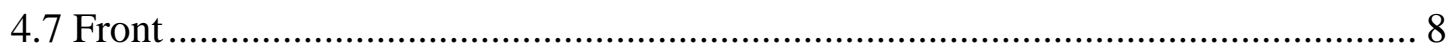

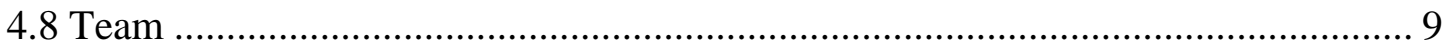

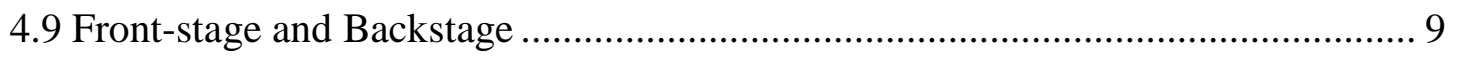

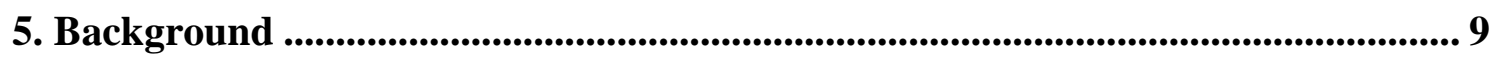

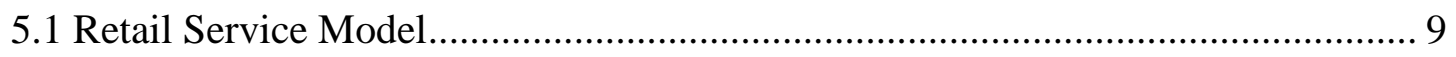

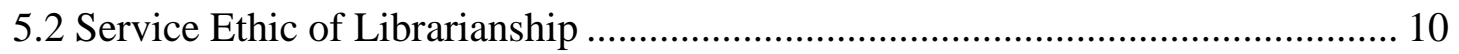

6. Review of the Literature................................................................................................ 11

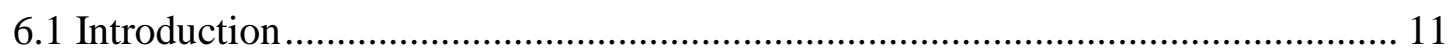

6.2 Is There Confusion Between What Librarians Perceive as Good Service and the

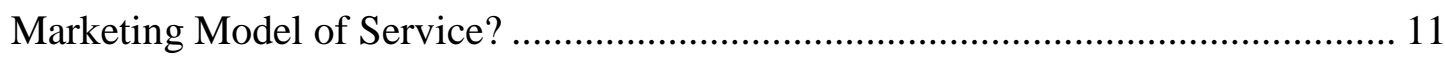

6.3 'Is Service Today Seen as a Weakness Instead of a Strength?' (Miranda-Murillo,

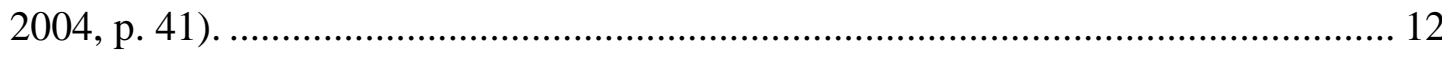

6.4 Do Librarians Feel They Already Offer Great Service? ..................................... 12 
6.5 How do Librarians Feel About the Word Customer?

6.6 How are Librarians Expected to Act? .............................................................. 13

6.7 The McDonald's Disney Service Model............................................................. 13

6.8 Criticism of the Retail Service Model ............................................................ 14

6.9 Why is the Retail Service Model Creating Tension? ........................................... 15

6.10 How is Service Behaviour Affected by the Culture of a Group? ....................... 16

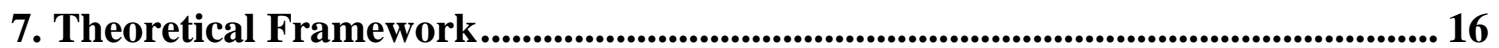

8. Research Methodology ...................................................................................... 18

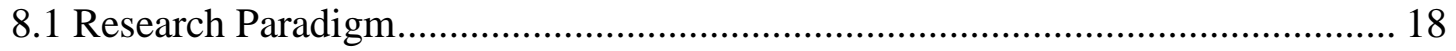

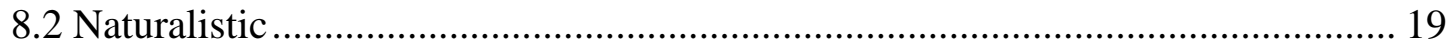

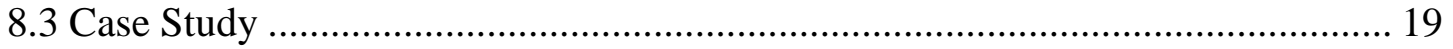

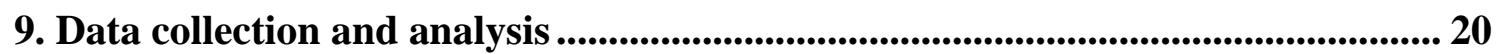

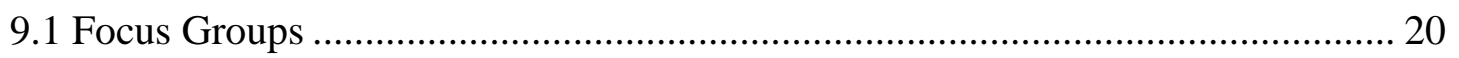

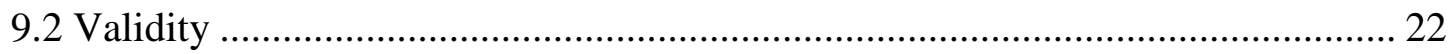

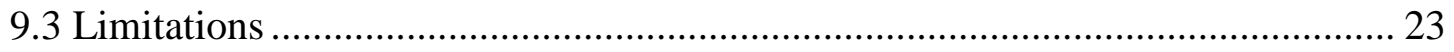

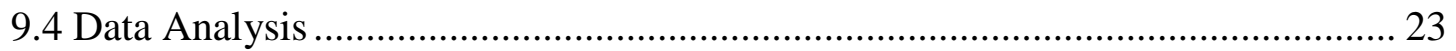

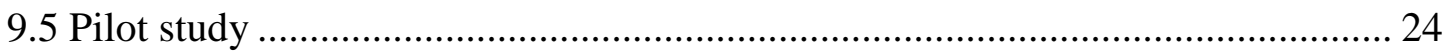

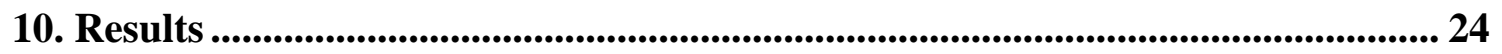

10.1 The Attitudes of Librarians in Relation to Service........................................... 24

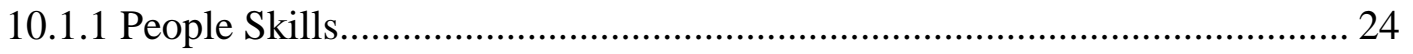

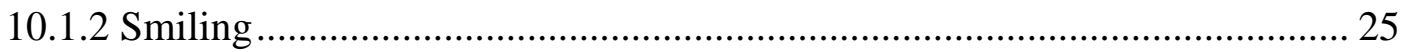

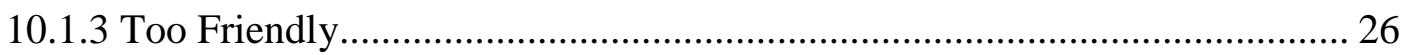

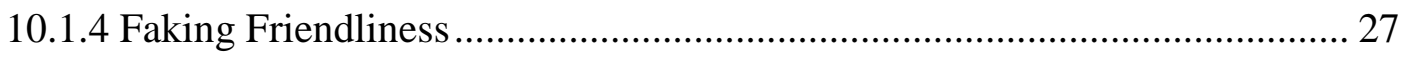

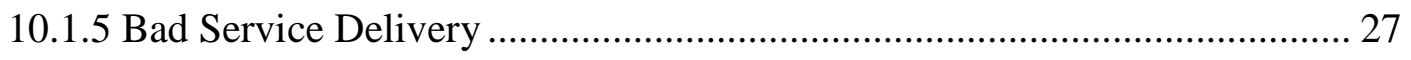

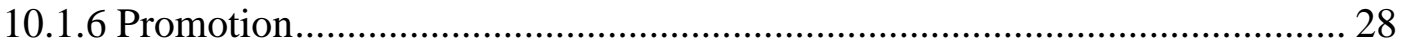


10.1.7 Solutions to Bad Service......

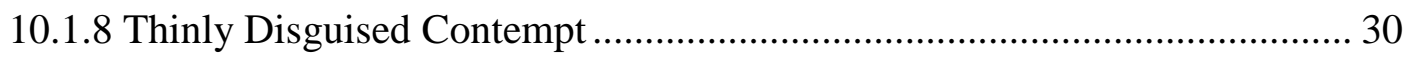

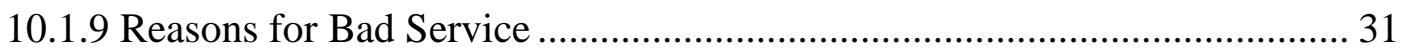

10.2 How the Culture of Service in Libraries is Shaped........................................... 31

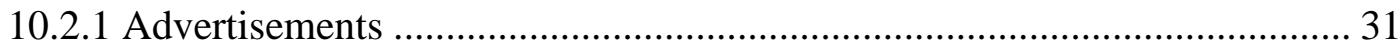

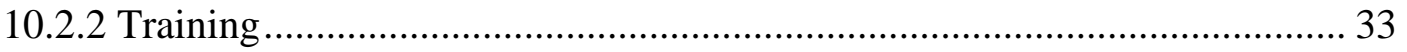

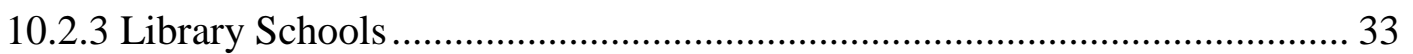

10.2.4 Influence of Colleagues .................................................................. 34

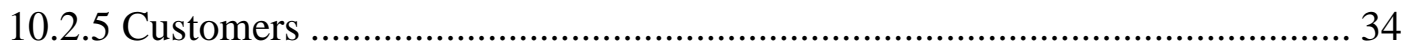

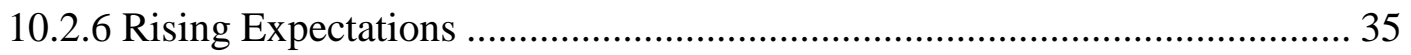

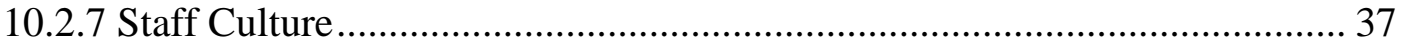

10.3 What the Retail Model Means to Librarians and how it Compares to the

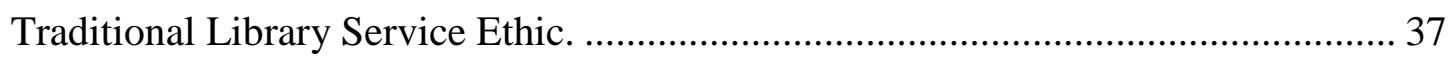

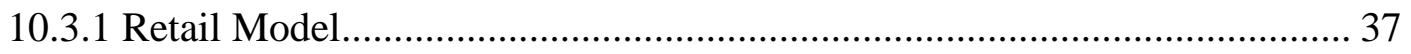

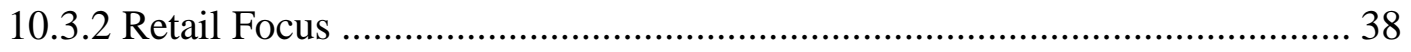

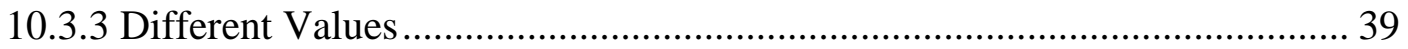

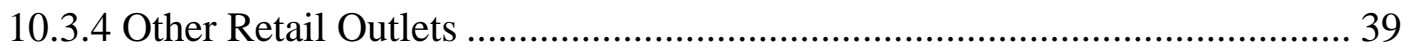

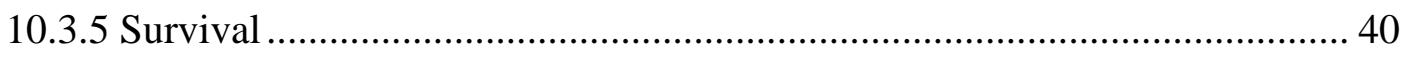

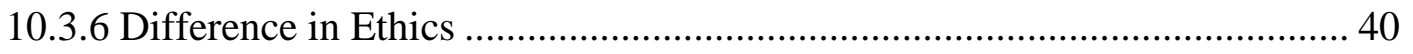

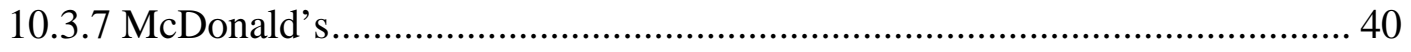

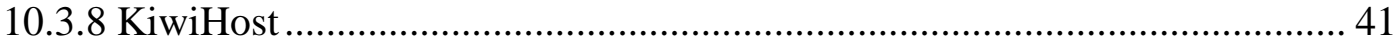

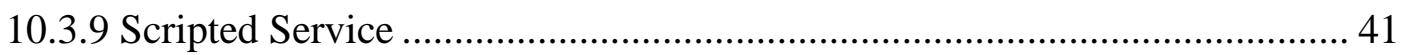

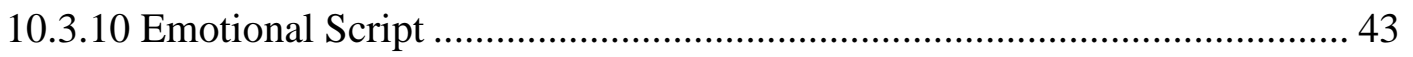

10.4 The Impression Librarians Aspire to Attain and how this Relates to Status. ..... 43

11. Analysis ........................................................................................................................................ 47 


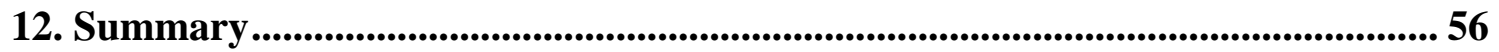

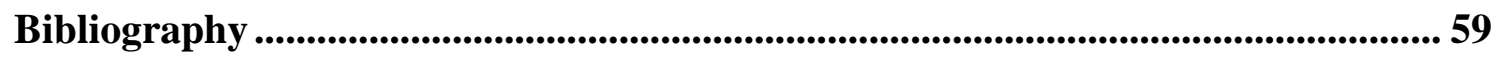

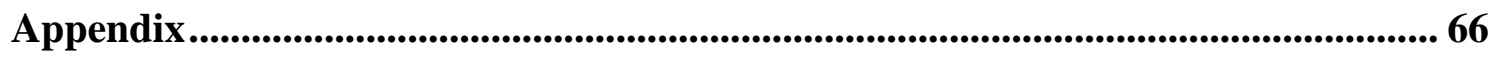

Appendix A: Information Sheet and Consent Form ….......................................... 66

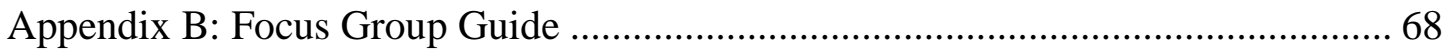




\begin{abstract}
The purpose of this research is to explore the attitude of librarians to service. Previous studies showed that although many librarians identified service as their most important value, librarians were still perceived by many customers as unfriendly and unhelpful. Using Goffman's theory of dramaturgy the study looks at the relationship between the library service ethic and the market driven service ethic attributed to retail, and whether there is conflict between these two models, and if so what affect this is having on the attitudes and behaviour of librarians. This qualitative study uses focus groups to gather data. Focus group participants were all practicing librarians from the Wellington area. The research concludes that there is a conflict between the two service models which is directly affecting the attitude and thus the behaviour of librarians. The marketing model is perceived as a threat to the core functions of libraries because of its 'one size fits all' approach to service. Participants felt this model was a threat to genuine authentic service and personal autonomy.
\end{abstract}

Keywords:

Dramaturgy

Status

Service

Attitude

Marketing Model

Retail 


\section{Introduction}

Librarianship is founded on a professional outlook that directly feeds into the sense of purpose and attitudes held by the individuals within it. Service is the most important ethic in librarianship (Gorman, 2003; Hauptman, 2004; Miao \& Bassham, 2007; Ranganathan, 1963; Rubin, 2000; St Clair, 1993). Well over half of the Codes of Ethics found on the IFLA website rate customer service as one of the most important values (Miranda-Murillo, 2004). Koehler (2003) notes librarians overwhelmingly identified service to the patron as their most important value. "Without doubt and almost without exception, librarians of all kinds, in all positions, in all regions, and of both genders identify service to the client or patron as their most important value" (Koehler, 2003, p.106).

In librarianship this purpose is defined by Rubin (2004) as service that not only meets the information needs of the individual but more importantly communicates knowledge for the betterment of the individual and therefore society as a whole. Rubin quotes Butler who states in 1951:

The cultural motivation of librarianship is the promotion of wisdom in the individual and the community...to communicate, so far as possible the whole scholarship to the whole community. The librarian undertakes to supply literature on any and every subject to any and every citizen, for any and every purpose... [These actions] in the long run, will sharpen the understanding, judgement and prudence of the readers and thus sustain and advance civilisation. (p. 304).

It is this very purpose that Rubin (2003) suggests separates librarianship from business, and thus retail, because business has profit as its fundamental purpose. 
Rubin feels that libraries that adopt a business model seriously distort their traditional service orientation. It is impossible to offer equality of service if information is marketed as a commodity. Gorman (2003) points out that because a business model has profit as the main motive it is impossible for libraries, under this model to fulfil their traditional values. "We believe in values that comfort the powerless and defend minorities in a world where the profit motive reigns virtually unchallenged. We stand for selfless service, equal access, and inclusiveness in a world of egos, exclusion and division" (P. 146).

The literature has found that librarians remain loyal to these traditional ethics and see retail outlets as unconcerned with genuine customer satisfaction. A participant in Fox's (2005) study claims that in bookshops the assistant does not care what an individual goes away with. Bookshops do not offer the same service as libraries because people do not get the quality of service that they receive in a library. Staff in bookshops were seen to lack knowledge and expertise and were unable to give the same level of service and advice as librarians, and did not even aim to, often talking rubbish (Fox, 2005). Quinn (2005) elaborates on this concern by suggesting that under the marketing model the appearance of expertise is more important than actual expertise. Librarians believe they offer genuine expertise and thus superior service to retail. The library service ethic is based on the premise that it is of higher value to be knowledgeable (Fox, 2005).

The retail model of customer service is often embraced by library bodies to enhance service and ensure libraries are customer led and not systems led. The guidebooks and how-to-do-it library manuals suggest librarians can learn a lot from the retail model on how to offer excellent service. Siess (2003) and Walters (1994) praise the 
McDonald's model because it raises the service bar and the expectation is that because of the homogenous nature of the service encounter all service encounters will meet certain standards.

Librarians have shown resistance to the retail model of customer service training. A librarian interviewed by Miranda-Murillo (2004, p.41) stated, "Why not go to the McDonald's University or work in a Wal-Mart if you want to learn how to provide service?" Bishop \& Bauer (2002), Paul (1990) and St Clair (1993) all state that when implementing service changes in libraries the attitudes of librarians was seen as an obstacle to success even to the extent of open hostility (Paul, 1990).

Although service is the most important ethic for librarians, studies show that the stereotype of librarians as unfriendly and unhelpful is alive and well (McArthur \& Nicholson, 2005; Massey-Burzio, 1998; Meyers, 1999; Owen, 1998; Urban Libraries Council, 2001). The marketing model has brought with it higher expectations of service and customers will no longer tolerate bad service (Deane, 2003). Quinn (2005) argues that the expectations may be unrealistically high. This raises many issues which this research hopes to address, mainly whether librarians are in any way reinforcing the unhelpful and unfriendly librarian stereotype.

Librarians have expressed hostility towards implementing the retail model of service in libraries. The feeling is that by embracing the service ethic librarians will not meet the needs of their public. Quinn (2005) suggests that if libraries embraced the retail model knowledge, substance and expertise would be replaced by appearance and impressions. 
Goffman (1959) uses the dramatic metaphor as a way to describe human behaviour, particularly behaviour that is usually hidden or taken for granted. The aim of this study will be to shed light on whether unconscious or hidden behaviour shaped by the culture of librarianship and displayed by librarians during a service encounter has any effect on service behaviour.

\section{Interest in the Topic}

I went to my public library to locate a journal article. I approached the counter and waited for the staff member to look up from his computer screen. He did so, seemingly unwillingly and gave me a lacklustre look. He was unable to locate the journal and sent me down a level to look amongst the magazine racks. I searched every row, couldn't find it so asked at another counter and was directed back upstairs with a wave of the hand. This woman also had a lacklustre expression. When I explained I had already been upstairs, she sent me to yet another counter. There were two people behind this counter. I waited for them to finish their conversation. They also tried to send me back upstairs. They spent some time looking at the screen and talking together. I said 'I just want to know where it is' The young man said in a very snappy tone. 'What do you think we're doing?' It turned out the journal was in the stacks. The woman retrieved a box for me, pointing out that I could not borrow the journals.

This service encounter displays many of the hallmarks of a problematic encounter documented in the library literature:

- Not looking up from your work or stopping what you are doing (McArthur \& Nicholson, 2005; Miranda-Murillo, 2004; St Clair, 1993).

- Focusing on the computer terminal (St Clair, 1993; Todaro \& Smith, 2006). 
- Not getting up to assist the customer (Massey-Burzio, 1998; Paul, 1990).

- Not seeming to be interested in being helpful (Massey-Burzio, 1998).

- Abrupt when asked too many questions (Black \& Crann, 2002).

- Being so absorbed in work that the customer feels like an intruder (McArthur \& Nicholson, 2005).

- Acting as if the customer is wrong, and if they can't find something it is their fault (Siess, 2003).

- Displaying an attitude of thinly disguised contempt (Barter quoted by Siess, 2003).

- Passing a customer from one staff member to another (Calvert, 2005).

Before becoming a librarian, I would have thought this was arrogance; that the librarians felt they were too good to be bothered serving me. Now that I am a librarian, I find my colleagues and the library community in general are not arrogant at all and are very committed to service. The reason for the bad service must have deeper origins.

When I read Goffman (1959) I felt that I was getting closer to understanding that this poor service behaviour may be connected to resistance in some way. Goffman gives the example of resistance by jazz musicians. When the musicians were asked to play corny music by the audience, they exaggerated the music making it a bit too corny in order to convey to the other musicians their contempt (Goffman, 1959).

Goffman's view is that social life is theatrical and playing roles is an essential part of socialization. The way people present themselves to others may not be conscious but habitual. A person downplays or hides actions that are inconsistent with their ideal (Quinn, 2005). Rodger (1998) notes that in times of change groups seek comfort by 
reverting back to their traditional historical values. Librarians enter the workplace with a sense of values that are already in place. The values are not generally discussed but define the culture.

\section{Aim of Study}

The literature addressing the value of customer service in libraries describes the application of marketing principles to increase customer satisfaction. This prescriptive literature views the market led approach in a positive light and is highly critical of the negative attitude displayed by the library community. Studies addressing the marketing model of librarianship indicate librarians have a negative attitude to this model of service, which they view as inappropriate for libraries. Although the library literature has identified that librarians have a negative attitude to the retail service model, the literature does not examine the reasons for this resistance in any depth.

This paper will explore the opinions and attitude of librarians to service, and whether during a service encounter the attitudes of librarians lead to unconscious behaviours that send messages contrary to the established service ethic of librarianship.

\section{This paper will aim to explore the following questions:}

- What are the attitudes of librarians in relation to service?

- How is the culture of service in libraries shaped?

- What does the retail model mean to librarians and how does it compare to the traditional service ethic?

- What impression do librarians aspire to attain and how does this relate to status? 


\section{Definition of Terms}

\subsection{Customer Service}

The term customer traditionally refers to a person who spends money for goods and services. Libraries have adopted this term for users and the implication is that they are called customers; a library is now primarily a place of service rather than a warehouse for old books (Miranda-Murillo, 2004; Siess, 2003).

\subsection{Face-to-Face Interaction}

Goffman (1959) defines the face-to-face interaction " $\ldots$... as the reciprocal influence of individuals upon one another's actions when in one another's immediate physical presence" (p. 15). Goffman makes the points that during a face-to-face encounter all the activities around this performance have an effect on it, so conversations with colleagues and behaviour learnt about the expectations of the performance are influential on the encounter. A successful service encounter is defined for the purposes of this study as having a courteous, helpful, caring, friendly and respectful attitude (Miranda-Murillo, 2004; Paul, 1990; Siess, 2003; Walters, 1994; Weingand, 1998). This service encounter is from the time an individual enters the library to the time they leave, and the manner in which they are welcomed and farewelled (Calvert, 2005).

\subsection{Traditional Library Service Ethic}

Customer service in libraries includes not only the individual customer but the community, and society as a whole (Ranganathan, 1963). Gorman (2003) describes the purpose of librarianship as the advancement of civilisation and promotion of the world's knowledge. Service is designed to bring knowledge to people and society (Rubin, 2004, p. 304). To successfully serve the community means being unconcerned with profit because service has to meet the communities needs all the time remaining 
mindful of equality, neutrality, privacy, freedom, equity of access, education literacy and life long learning (Koehler, 2003; Gorman, 2003; Rodgers, 1998). Gorman (2003)

\subsection{The Market-Led Approach to Customer Service}

Modern marketing methodology is focused on the customer. Market requirements are influenced by ever rising expectations of service, and good service is seen as the key ingredient to attract and retain customer support (Branding UK; Hernon \& Altman, 1998; Siess, 2003; Laser Foundation, 2004; Miranda-Murillo, 2004; Shontz, Weingand, 1997).

\subsection{Status}

Attaining the standards, conduct and appearance that one's social group also attaches value to (Goffman, 1959). Johnstone (1981) defines all transactions as status transactions. "Every inflection and movement implies a status, and...no action is due to chance, or "motiveless"” (p. 33).

\subsection{Impression Management}

Goffman (1959) uses this expression to describe an individual's management of their interactions. The individual creates a believable impression to others that meets the expectations of their social group. This includes how individuals manage their face and voice expressions to match expectations.

\subsection{Front}

A front is the communication of a believable performance. The front is made up of:

- The setting which includes the layout and the way the space is physically presented, including the layout, furniture and equipment. These are referred to as stage props. 
- The personal front which includes manner and appearance which encompasses dress, facial expressions, gestures, personality and demographic profile (Grove \& Fisk, 1983; Quinn, 2005).

For the purposes of this study the focus will be on the personal front particularly manner because "Manner refers to those cues that indicate the role a performer expects to play in a situation" (Quinn 2005, p. 333).

\subsection{Team}

Team is the term given to a group of individuals who cooperate to create a single definition of reality. Team members interact to form a single impression. This impression does not necessarily reflect the person as an individual but who they become when belonging to a certain team/group (Grove \& Fisk, 1983).

\subsection{Front-stage and Backstage}

- Front-stage is area where the performance or interaction takes place and where the audience are present.

- Backstage is the area that is usually hidden from the audience and it is where the actor can drop out of role. Backstage is where much of the learning and rehearsing takes place to perfect the front-stage performance (Goffman, 1959).

\section{Background}

\subsection{Retail Service Model}

The market-led approach to customer service emerged during the 1980s (Fox, 2005; Calvert 2000). The new market based economy brought with it market based accountability based on a business model in which all energies are directed toward satisfying the customer (Miao \& Bassham, 2007). Market requirements are being influenced by the rising expectations of service, and good service is seen as the key 
ingredient of success to attract and retain customer support and satisfaction (Hood \& Henderson, 2005; Hernon, Nitecki \& Altman, 1999; Kerr, 1999; 1998; Siess, 2003; Laser Foundation, 2004; Miao \& Bassham, 2007; Miranda-Murillo, 2004; Shontz, Parker \& Parker, 2002; Todaro \& Smith, 2004; Walters, 1994; Weingand, 1997).

This transition to market driven libraries is said to have come about for a variety of reasons though essentially all relate back to budget cuts through loss of patronage (Miao \& Bassham, 2007; Miranda-Murillo, 2004). From this it has been concluded that if libraries are going to survive as future information providers, they need to be customer focused (McArthur \& Nicholson, 2005; Massey-Burzio, 1998; Paul, 1990:

St Clair, 1993; St. Lifer, 2001, Weingand, 1997).

\subsection{Service Ethic of Librarianship}

Service is a core value and mission of Librarianship (Gorman, 2003; Hauptman, 2004; Miao \& Bassham, 2007; Ranganathan, 1963; Rubin, 2000; St Clair, 1993). Gorman (2003) refers to service as the golden thread that runs through all libraries. The American Library Association states "We provide the highest level of service to all library users through ...courteous responses to all requests" (American Library Association Policy Manual, 2007, p.14).

The library service ethic is steeped in values that place librarians in a high status role; as guardians of knowledge contributing to the progress of civilisation (Foskett, 1962), as moral educators (Rodger, 1998) and as cultural stewards (Miao \& Bassham, 2007). The retail service ethic is viewed by librarians as commercial and unconcerned with community issues. If librarians embraced this retail model they could jeopardise their 
values (Black \& Crann, 2002). Rodger (1998) points out that it may not be healthy for librarians to hold onto traditional values which see their role as moral educators. Massey-Burzio (1998) and Siess (2003) feel it is essential librarians bypass their deeply held service values because it means librarians are too focused on what is supposedly good for the patron.

\section{Review of the Literature}

\subsection{Introduction}

This review explores literature relating to the retail model of service as it applies to libraries. It also explores research that closely examines the attitudes of librarians to service most notably Fox (2005) and Miranda-Murillo (2004). The review also examines literature that applies Goffman's dramaturgical model, most importantly Wager (2007) and Quinn (2005). Also explored is the growing field of literature on service industry expectations and consumer resistance.

\subsection{Is There Confusion Between What Librarians Perceive as Good Service and the Marketing Model of Service?}

Miranda-Murillo (2004) found that service in librarianship was not clearly defined.

Library schools considered that they were teaching customer service because it was embedded in all courses. Teaching actual customer service techniques was considered non-professional. "You don't waste a whole degree training people in service!" (p. 41). Fox (2005) also acknowledged that library staff were unclear about the role of libraries as customer expectations continued to increase. Shontz, Parker \& Parker (2002) identified that librarians had a negative attitude towards the commercial customer service model. 


\section{3 'Is Service Today Seen as a Weakness Instead of a Strength?' (Miranda-Murillo, 2004, p. 41).}

St Clair (1993) states that librarians fear incorporating business practices into libraries. St Clair questions this fear and asks if it is because librarians perceive themselves as having a higher purpose that precludes them from tarnishing themselves by using the same methods and techniques that are used in the business world ( $\mathrm{St}$ Clair, 1993, p. 14). St Clair recommends that librarians accept that they are part of the service industry. Realising this will not mean librarians have to give up their position of strength. This suggests that librarians perceive accepting the service model as a lowering of their status and thus weakening their position.

\subsection{Do Librarians Feel They Already Offer Great Service?}

Siess (2003) and Walters (1994) note that libraries often find that the implementation of customer service programmes is unsuccessful because librarians are resistant to change and often feel they already offer great service. Many see customer service training as a passing fad and an insult to their intelligence and professionalism to be trained to smile. (Fox, 2005) recounts a study undertaken by the North Yorkshire County Council. The study used a retail-based training programme offered by an external company to improve customer service skills of frontline staff. Many of the staff felt they did not need the training as they felt they were already good at delivering customer service, although it was observed that many of them were in fact dreadful. St Clair (1993) discusses a study he conducted with Andrew Berner in 1991 on the customer service attitudes of librarians in Australia. They were both surprised at the resistance they encountered from librarians to the concept of customer service. They believe this is because librarians perceive themselves as inherently good and as moral arbiters of the dissemination of information. This view is backed up by Siess 
(2003). Paul (1990) and Walker (2007) also discovered that librarians displayed both overt and covert hostility during customer service training.

\subsection{How do Librarians Feel About the Word Customer?}

Participants in Fox's (2005) and Black and Crann's (2002) studies expressed dislike of consumerist language such as 'customer.' Many librarians do not like referring to their patrons as customers because it implies the exchange of money (Fox, 2005;

Siess, 2003). These librarians believe that libraries could not be customer-led in the same way as retail because retail outlets were associated with profit. Bookshops are thus not perceived as competition because bookshops did not care what they offered customers (Fox, 2005; Paul, 1990; Siess, 2003).

\subsection{How are Librarians Expected to Act?}

The customer service guides give very clear instructions on what is expected during a service encounter based on a retail service model. Librarians should smile (Walters, 1994; Weingand, 1998), display empathy (Walter, 1994), have good listening skills (McArthur \& Nicholson, 2005), make eye contact (Koontz, 2002; Miranda-Murillo, 2004; St Clair, 1993; Walters, 1994), be approachable through body language with no hands in pockets, clenched fists or folded arms (Walter, 1994). A good tone of voice is also expected (Todaro \& Smith, 2006; Walter, 1994). This is achieved by perceiving and thinking about customers with a positive and caring attitude (Miao \& Bassham, 2007; Miranda-Murillo, 2004).

\subsection{The McDonald's Disney Service Model}

The prescriptive literature views the retail model of service as appropriate for libraries. Guidebooks praise the McDonald's service model. Siess (2003) and Walters (1994) say that elements of the Disney and McDonald's model have raised the service 
bar and the definition of service. Walters (1994, p.11), in her book Customer Service: A How-To-Do-It Manual for Librarians suggests librarians can learn from the Disney McDonald's model where every customer is a VIP. In a McDonald's restaurant, customers are greeted cheerfully and sincerely. Librarians themselves do not hold this model in high regard. Participants in Black \& Crann's (2002) research said they believed that the Disney model represented a dumbing down of libraries.

\subsection{Criticism of the Retail Service Model}

Sturdy \& Fineman, (2001, p.135) are critical of the approach to service in which an organisation requires a certain behaviour, attitude or tone from their workers. Workers are required to display emotions like passion and enthusiasm. They refer to this approach as emotional management. Workers may be resistant to emotional management because their cues are derived from the emotions that they perceive as suiting the situation and the culture of a group. John (1996, p. 2) adds that all service encounters are performed within the context of the cultural background of the participants, so therefore culture must play an important, if sometimes unrecognised part in the service encounter. The cultural orientation of a person is expressed through the attitude and thus the behaviour one thinks is appropriate and effective in a given situation. Sturdy \& Fineman (2001) suggest the status is already embedded in a culture. Resistance comes about when people feel morally compromised. Not all employees embrace the customer service training ethic of being friendly and caring, feeling it is a false niceness. Resistance takes the form of anger, frustration, resentment or cynicism as a way of maintaining a feeling of autonomy and self worth. Sturdy \& Fineman also note that consumer resistance to emotional management has yet to be fully researched. 


\subsection{Why is the Retail Service Model Creating Tension?}

Quinn (2005) suggests education and experience is downplayed in favour of interpersonal skills and attitudes with qualities like enthusiasm. The appearance of expertise is more important than actual expertise 'Style takes precedence over substance in a culture in which impressions are critical' (Quinn, 2005, p. 349). Quinn blames the marketing model of service for this emphasis on appearance over expertise. It could therefore be argued that the dilemma in the library world is the collision of the two service models.

Quinn applies a dramaturgical framework and thus refers to customers as the audience and librarians as performers and crowd pleasers. Quinn questions how discerning or critical the audience is. "In a culture where much of what is done is intended to keep them satisfied and ensure that they will be a loyal audience that keeps returning ...there is a danger that the audience will become more interested in the spectacle than in the ideas it was originally intended to convey" (p. 350). Korczynsi (2001) says that customers now evaluate the service interaction rather than the product. Sturdy (2001) refers to the customer as 'all powerful' and questions whether they actually know what they want. Customer expectations are being constantly raised and customers are given higher status. Quinn (2005) sees the application of the marketing model the greatest challenge facing (academic) libraries in the future because librarians still need to offer real substance in the form of resources and expertise that goes beyond appearance and impressions to an audience with ever growing expectations created by a culture of hyperbole (Quinn, 2005, p. 350). 


\subsection{How is Service Behaviour Affected by the Culture of a Group?}

Wager (2007) applied Goffman's dramaturgical framework to explore the front-stage and backstage behaviour of car salespersons and service advisors in a car retailing company. The backstage learning and front-stage behaviour was markedly different between the two groups. The car salespersons thought more in terms of customer satisfaction and the relationship with the customer. High value was placed on excellent service and selling was seen as enjoyable. While for the service advisors customer service was a low priority and a high priority was placed on knowledge of cars. The service advisors were socialised to perceive customers service as a less enjoyable aspect of the job. Much of this social learning takes place backstage, and a key finding in Wager's study was the non-constructive role backstage learning could have on behaviour "...members of a community can learn to think and behave in ways that can diminish a service culture and ultimately, service quality. If the group culture does not prioritise the provision of good service, the quality of the role performance is weakened" (p. 651).

\section{Theoretical Framework}

(Pickard, 2007, p. 39) states that a “...theoretical framework covers theories, concepts and issues which surround your chosen topic." The theoretical framework chosen for this research is Goffman's theory of dramaturgy. Goffman's dramaturgical model was chosen because by viewing people as if they are actors one can describe human behaviour, particularly behaviours that are usually hidden. Both Quinn (2005) and Chelton (1997) suggest that this model would be a useful framework to explore library culture because behaviours in libraries is often neglected and taken for granted. Chelton (1997) describes Goffman's framework as a way to understand and derive meaning from everyday social situations because every day interactions are in fact 
highly ritualised. The service encounter “...provides an ideal exemplar for examining these invisible, taken-for-granted rules, and mismatches because they provide our understanding of larger social structures through our experience of them in repeated interactions (Chelton, 1997, p. 389).

Goffman uses the dramatic metaphor to describe the face-to-face interactions between people. All social groups convey a certain impression in keeping with what is defined by the group. Solidarity develops within the group and members are selected who are loyal to those ideals (Goffman, 1959).

Goffman's dramaturgical framework uses theatrical metaphors and thus in a service environment service providers are actors or performers and customers are audience members. The actor presents a front which is the performance. Goffman (1959) states that in service occupations actors may believe they are presenting a sincere front and believe their own act, or they may be cynical about the act they are expected to perform. Goffman also uses the theatrical metaphor of front-stage and backstage. Thus, a good face may be presented to the public who are belittled and criticised backstage.

According to Goffman a social front becomes institutionalised and can take on a meaning and stability apart from the specific tasks. The front then becomes a collective representation. And when an actor takes on a role they usually find a particular front has already been established (Goffman, 1959). This suggests that a stereotype is difficult to change. An example in librarianship may be that the rhetoric contained in a job description does not match the actual behaviour of the appointed person. Everyone knows this happens but it is accepted. 
Goffman asserts that during face-to-face contact individuals convey a certain impression that is in their best interest, thus it is an impression they choose to convey, that shows them in what they perceive as a favourable light. This may not be entirely conscious or calculated, as the favourable light is often more closely connected to the culture of the group than it is to the individual's behaviour, because an individual's behaviour is designed to meet the culture and social status of the group. Goffman points out that an individual does not usually have the power to change this set behaviour because the front has already been established.

In this research Goffman's theory helped contextualise behaviour and inform the research. The researcher did not decide in advance what kind of evidence and explanations she would come up with. She let the theory emerge to avoid narrowing the focus, making assumptions and blocking development (O'Connell, Davidson \& Layder, 1994).

\section{Research Methodology}

\subsection{Research Paradigm}

A qualitative research method was chosen allowing for an interpretivist paradigm. A paradigm is '...the entire constellation of beliefs and values.' (Kuhn quoted by Pickard, 2007, p. 6). Pickard divides these beliefs into three research paradigms: positivist, post-positivist and interpretivist. Guided by the work of Pickard (2007) an interpretivist paradigm was chosen. Firstly because it most closely matched the researcher's world view, that reality is socially constructed, complex and ever changing (Leedy, 1997) and secondly because "Interpretivism can offer understanding of the meanings behind the actions of individuals" (Dervin quoted by Pickard, 2007, p. 12). The researcher is therefore not so bound by parameters and theoretical 
assumptions. Opinion can be part of the research. This process allows greater freedom to be open to the particular setting and subjects, allowing these to inform the process and even modify the research plan (Gorman \& Clayton, 1998).

The interpretivist paradigm aligned itself with the research problem because realities are seen as multiple and embedded in the context of the situation (Pickard, 2007). Communication is also not context free. People respond to different situations playing different roles. Using Goffman's dramaturgical model in an interpretivist framework helped the researcher look at how actions were defined by the environment. It provided a way to frame and describe social behaviour. The desire was not to come up with quantifiable answers or generalisations but to look for patterns in the attitudes and values of librarians.

\subsection{Naturalistic}

Naturalistic inquiry was chosen as the approach to interpretivism. Guba and Lincoln (1981) use an onion metaphor to describe naturalistic inquiry. Each layer of the onion represents a reality. No layer can be accepted as a single truth or understood separately from the others.

\subsection{Case Study}

Gorman \& Clayton (1998) recommend the case study for an inexperienced researcher because it offers boundaries that help limit the research to a particular activity, people or place. Pickard (2007) views the case study as in-depth and existing within a real life context. Case studies are useful in shedding light on a phenomenon whether it be an issue, problem or object. The idea is to produce a detailed description of the case. (Leedy, 1997). 
Case studies are flexible and multiple cases can be studied to draw comparisons (Leedy, 1997). Gorman \& Clayton (1998) explain the constant comparative case study approach developed by Glaser and Strauss. This offered a useful structure on which to hang the research. This method is one of constant comparison of sources. Data analysis, creation of categories, collection, writing and coding happened throughout the process.

\section{Data collection and analysis}

\subsection{Focus Groups}

Data was collected through focus groups. Focus groups were chosen as a self contained means of collecting data. Morgan (1988) states that no further data collection method is necessary. The data in this case was compared with the literature to enhance validity.

Focus groups were chosen as the method of data collection because they are exploratory in nature (Morgan, 1988). A group situation is a good way to discover the interests, opinions, perceptions and feelings of a group who interact with each other, not just the interviewer (Kruegar, 1994; Morgan 1988; Stewart \& Shamdasani, 1990). The group situation was useful because comments made by one participant prompted other participants to share their opinions. This created a feeling of security and people felt less exposed or defensive (Goulding, 1997; Morgan 1988; Stewart \& Shamdasani, 1990).

The research required participants to look at behaviour and motivation that they had previously not given much thought to. Calvert (2001) suggests a focus group is useful when issues to be discussed by participants may be awkward or confusing because ideas and opinions are shared. Langford \& McDonagh (2003) states that focus groups 
are good for looking at complex behaviour such as motivation and responses that are not necessarily thought out in detail and can provide insights into unconscious beliefs.

Focus group sizes were kept small. Kruegar (1994) states that large groups are too big for complex topics and smaller groups are easier to moderate and offer greater opportunity for participants to contribute. Big groups would have required too much moderator involvement (Kruegar, 1994; Morgan, 1988; Patton, 2007). Eighteen people were selected to take part in the focus groups. Fourteen of these took part.

Three focus groups were conducted during the month of April. Kruegar (1994) considers between three and six groups as adequate because trends will appear by this time. The researcher found that the data generated from all three focus groups was very similar. If a moderator can clearly anticipate what will be said next in a group, then the research is done; this usually takes three or four groups (Morgan quoting Calder, 1988, p. 42).

Participants were practicing librarians from the Wellington area. The first participants were selected using convenience sampling and subsequent participants selected using purposive snowball sampling. Once themes had emerged during the first focus group session the researcher sought participants to ensure the population sample met the purpose of the research. Thus participants were chosen who had varying length of service, from both sexes and with varying personality traits including both introverts and extroverts. The focus group sessions ran for between forty five minutes to one hour.

The library community is a small one and so there were people in every focus group who knew each other. This was not considered a hindrance as Morgan (1988) notes 
participants need to feel comfortable with each other to aid open discussion and Kitzinger (1994) said that friends and colleagues have the advantage of relating to each other's comments. Friends can more easily challenge contradictions between professed behaviour and actual behaviour.

A high level of moderator involvement was chosen to ensure all topics were covered and to probe more deeply when required (Goulding, 1997; Morgan 1988). The conversation was still left to flow naturally as Morgan (1988) suggests, and the conversation was not over directed. This allowed unexpected and interesting issues to emerge. Participants were allowed to speak for themselves because if the moderator is too involved it can lead to bias, participants then reflect upon what they think the moderator wants to hear (Goulding, 1997; Morgan, 1988).

\subsection{Validity}

Kruegar (1994) defines validity as the degree in which the procedure actually measures what it is supposed to measure. Kruegar suggests validity can be assessed using face validity. This means the researcher asks him/herself if the results look valid. Gorman \& Clayton (1998) refer to this as sense making. When the researcher is clear that the behaviour is appropriate for the population that is being studied then the phenomenon can be freely explored. The researcher used face validity to assess the data in this project.

The study also used the following strategies to help ensure validity:

- Conducting a number of focus groups because repetition creates a more reliable and thus valid picture (Gorman \& Clayton, 1998).

- Including a large selection of transcript material in the reporting.

- Triangulating the data by matching it with previous studies. 


\subsection{Limitations}

This study is limited by the small sample size and the fact that participants were selected from one geographical area in New Zealand. It is impossible to know if the researcher captured the range of opinions and attitudes of librarians in general. This study offers itself as a discussion to further understanding of behaviour.

\subsection{Data Analysis}

Focus group discussions were taped and later transcribed. Before the tapes were transcribed they were listened to for sense making. Notes were jotted down during this process. Tapes were then transcribed and interpretative thoughts were jotted down in the margins. This way one is working with the complete transcripts as a whole (Gordon \& Langmaid, 1988). Transcriptions were then coded using an open coding process of examining each line then defining actions and events. Coding this way keeps the data studied (Strauss, 1987). Questions were then asked and a number of possible different coding criteria emerged, though many were later abandoned, because Strauss (1987) warns that when analysing the data one must not become too committed to the first codes as they may not be as relevant as they first appear to be. Coding was regularly interrupted to write as suggested by Strauss (1987). This also suited the case study method of analysing, creating categories, collecting, writing and coding throughout the process.

Themes emerged and categories were constructed. These were as follows:

- Resistance to service.

- Issues given high/ low priority.

- Values and ethics.

- Status

- Changes of opinions and self contradictions. 
- Differences in attitude between participants.

- Responses rewarded by the group (Goldman \& McDonald, 1987).

\subsection{Pilot study}

A pilot study was conducted with one experienced librarian. The pilot study helped clarify which questions would generate discussion and which questions were not clearly defined, or could possibly be misinterpreted. Significant changes were made and another experienced librarian was selected to test the questions. This successfully demonstrated that the questions were clear and gave the researcher confidence, as both participants were quite animated during the sessions.

\section{Results}

The research questions that guided this study are:

- What are the attitudes of librarians in relation to service?

- How is the culture of service in libraries shaped?

- What does the retail model mean to libraries and how does it compare to the traditional service ethic?

- What impression do librarians aspire to attain and how does this relate to status?

The data has been divided into sections that best answer the research questions.

\subsection{The Attitudes of Librarians in Relation to Service.}

\subsubsection{People Skills}

Focus group participants all agreed that it is essential to have an interest in people to work as a librarian. They used the following terms: most definitely, it is essential, it is a requirement, it is obvious and it is mandatory. Participants felt that librarians who did not have an interest in people were in the wrong job. 


\subsubsection{Smiling}

All agreed librarians should smile:

If you were required to provide a smile and you couldn't do it then it's the wrong job for you isn't it.

Basically a librarian should be friendly and smile but librarians should not be forced to be friendly or smile. Participants felt librarians smile without prompting:

I think you do it automatically anyway.

Because a number of participants felt smiling was something librarians did automatically as part of good customer service, the idea of enforcing a smile was viewed negatively:

They have to give a clear description of what that smile would entail...measurement, how much teeth do you show?

Some people may um you know they may smile already, like many of us and just the fact to make you smile I think I might go bugger them.

It's kind of fake, like would you like fries with that.

...you can't make a person smile.

There's a difference between enforced friendliness and just being polite.

One participant described enforced smiling in a retail outlet:

I used to work at Burger King, we had this pitch, this is exactly the steps you should go through and we had to enter the smile zone and I 
hated having to smile sometimes because we just got sick of it when people were rude to you, so I think there's an element of you being polite during each interaction.

\subsubsection{Too Friendly}

Participants thought one could be too friendly, being too friendly involved acting in an over the top way, being pushy or too personal or talking too much:

Oh yes definitely, like those people who ring you up doing surveys and say 'how are you tonight?' and I always feel like snarling you know 'what business is it of yours?

...you should be polite at a public desk; you don't have to offer them a drink.

Being too pushy otherwise you drive people away....

You can be polite but you wouldn't run over and give them a hug.

Especially if you know it's quite fake, like when a telemarketer gets on you're just like (...).

One participant described the way she thought librarians should act:

I think you've got to catch people's eyes and be receptive but not necessarily go chasing them, asking them if they need help unless they're obviously lost.

Interestingly two librarians from different groups described themselves as too friendly. Being too friendly was not viewed as appropriate behaviour and both of these librarians had been openly criticised for being too friendly. 


\subsubsection{Faking Friendliness}

The focus groups all agreed you could fake friendliness and suggested that working with the public was a performance. Therefore the customers are an audience.

Yeah, it's all about performance it doesn't matter if you're having a crappy day, you go out there and smile (...).

You can certainly fake, you can put on a performance when you're on the desk.

You have to its part of the job.

It's called being professional.

\subsubsection{Bad Service Delivery}

It was accepted that there are librarians who work with the public who are not good at service delivery:

Some librarians don't like people, they don't it's true.

There are some people at [library name] that fall into that category and they're still working at the front desk.

One focus group continued as follows:

It's a requirement at [Library name] for all staff to actually have a desk shift at some point in the week and that includes our cataloguing and our acquisitions staff who are totally not tailored for working on the front desk.

How does that work? 
Um it doesn't.

No?

It's actually one of our greatest failures.

Why do you do it? Why is it done?

The theory is that by being in touch with the clients or the students they actually get a feel for those needs that the students have and they can provide a better service out back with being in touch with that...

Most focus group participants felt that librarians who did not have people skills should not work with the public if they did not want to:

You've got to want to do it; you're not going to be happy if someone's forced you to do it.

Others felt that librarians who were not good with the public should still serve the public:

Yeah, it depends on the demands of the library really. Here you couldn't take somebody off the desk just because they weren't good at it because then everyone else would be spending more time there.

\subsubsection{Promotion}

Librarians who delivered bad service were said to be just as likely to be promoted and sometimes even more likely:

Sometimes people get promoted so that you can get rid of them. 
Promotion is not always based on merits.

We can laugh but it's usually what happens.

A couple of participants said librarians were often moved on to other library jobs with good references to get rid of them.

That's what people do though they give them a good reference and then somebody else gets stuck with them.

\subsubsection{Solutions to Bad Service}

Focus groups discussed solutions to the problem of librarians delivering bad service. Suggestions were made such as:

...tailoring them towards something they might really want to do...if they really don't want to work in customer services...instead of trying to waste our time getting rid of them, we'll see if there's actually somewhere more valuable they can work.

This was echoed by another participant who said:

... if you took somebody say in the National Library and you put them on the desk where they didn't really want to be and they weren't happy then the best thing to do would be to put them back where they belong.

Other participants felt that this was rewarding bad behaviour. It was too bad ...it's just part of the job. All jobs have grotty bits. But it was agreed it is very hard to get rid of people. 


\subsubsection{Thinly Disguised Contempt}

Participants understood precisely what this term meant. Two participants admitted to behaving in such a way if somebody ... treats me you like their slave and I'm just like I'll do it but.... Most participants had observed this type of behaviour.

One participant said:

I think we have to get rid of that image. Someone who didn't like dealing with people wouldn't be hired for a retail position, so you've got to sort of think should they be hired for a library position?

But it was agreed that it was not easy to deal with this problem as one can get ...a very bad response trying to step in and say something to the offender. Participants from two different focus groups used the expression bad response. Dealing with colleagues who deliver bad service was challenging. Two participants said they were too chicken. A librarian who had tried it did not recommend it. Trying to step in subtlety was considered. One person said: the situation won't change unless people speak out. Another participant said:

A lot of staff are just shy about doing it, but you've got to ...my reaction is to say have you spoken to the person about this first because I think it's really their place if they've experienced the actual problem or the issue. They've seen it and they should be talking to them and if they don't feel they're getting anywhere or they get a bad reaction then take it to somebody else.

Participants responded to this by saying it takes courage and training.

I've worked in really small teams and if you rock the boat with one person it wrecks the entire culture of the group. 
Many participants said they would not report bad service to management unless it was really bad.

\subsubsection{Reasons for Bad Service}

Being under resourced was given as a reason for bad service if people are burnt out and tired this will affect how they handle customer service. The retail model was also blamed for bad service because it created a false perception:

We're providing a service but there is an expectation that there is some education behind the person who is serving in the library but with the shift to the retail model I've seen in some of the libraries these young people don't have education they don't have anything to back that, but there's still the perception that they do and it's somewhat a false pretence.

Two participants admitted they did not always deliver good service, depending on circumstances such as having to spend too much time on the information desk. The desk could be exhausting. A participants who was in a management position expressed relief that she no longer worked at the front desk.

\subsection{How the Culture of Service in Libraries is Shaped.}

Goffman (1959) sees the culture of an organisation as the foundation stone that shapes behaviour. The culture of a group can be shaped most significantly by its history and through the influence of colleagues and the perceptions held about customers. Organisations attempt to reshape cultures through advertising and training.

\subsubsection{Advertisements}

Job advertisements using with phrases like ... are you passionate about customer service? ...you'll be brimming with energy and enthusiasm were seen as representing 
the new breed of librarian. Many participants thought they were part of this new breed. I'm not the stereotype, people like us, yeah that's me and it is changing.

Advertising was seen as a way to change the culture because librarians could not be trained to like people:

So for us I think it's fair to say that we're looking for those customer service skills and personality and things like that and whatever experiences other people may have because you can't train for those really and you can't learn those skills whereas it is still possible over a period to have in-house training to pick up the elements of basic librarianship.

Hire for attitude and train for skill.

Some participants did feel these advertisements were overstated:

These ads that state lots of qualities for the job interviews most of the time you overstate what you can really do or your qualities just so you can get the job s you know they might be over pushing it, but in the end we all know what's going to happen or most of the time.

One person even suggested there was a downside to over enthusiastic people:

I actually think of somebody who used to be on the staff at my work, that's exactly what he was like brimming with enthusiasm, motivation. We had somebody that had all that and he was absolutely exhausting. He was always sort of dragging people into things. Yeah I think those ads usually overstate things a bit. 


\subsubsection{Training}

In one focus group everyone agreed that people could not learn to be a people person:

I think you've either got it or you don't. You either like people or you don't.

It can be very difficult for extremely shy introverted people. I mean it's just with the best will in the world they're just not going to be comfortable.

\subsubsection{Library Schools}

Library schools were seen as unsuccessful in trying to change the culture:

When I applied for library school and I saw the form to be my reference to go up to Vic and they said we don't want any sweet nice sort of shy people we want exuberant sort of keen and enthusiastic people and that was 1988. And you still see students coming out who are drongos (laugh) and they're hiring them.

I've been up at that school for four years and I've seen some introverted personality less drongos coming out and I have no idea how they pass.

When you had to do interviews, this was the Eighties and it was a limited intake and I think they were trying to get rid of them then but we're not a sheltered workshop I don't know why people like that keep applying.

They think it's nice to work in a library you get to read books.

Two participants mentioned that it was not only library schools that did not focus on customer service but library jobs: 
It's interesting I can't think of any place I've worked in where you're actually monitored or put on trial for your customer service are you? It's only if they pick it up along the way that you mightn't be any good, but you know about the interviews. I remember going to an interview somewhere and they go here's a pile of legislation put it into order and file it away kind of thing. But no one would ever actually sit you down and role-play a, you know, a reference interview or how you'd deal with (...).

\subsubsection{Influence of Colleagues}

When exploring the impact of conversations with other colleagues in learned behaviour the following was read out: If the students are not going to bother coming in to the training sessions we offer, then we shouldn't bother helping them too much.

Participants felt that these sorts of conversations between staff members did have a negative effect on face-to-face behaviour:

Well you're going to be really negative to that student because they didn't turn up and come to the session and 'how dare you not turn up and come to the session, I'm not going to help you go away'.

Well I'll help you but (...).

\subsubsection{Customers}

All focus groups described situations where their services were used inappropriately:

Sometimes we get people who should have really gone to the public library and you do, I do get a bit of a bee in my bonnet.

We had a woman come in today asking about carrots and I just feel as if there are times when I think people aren't here for the right reasons and I did help her and often they don't help themselves and it's the same thing not turning up 
to training sessions if you're not prepared to help yourselves and they give them other chances but if they've never taken up.

I do frequently find myself thinking that a lot of the students come in here need some sort of course back at source.

That's the problem, they never do. I never did one when I was a student because I couldn't be arsed, and I know when I worked at [library name] we had this conversation and the people running the curriculum basically just said there's no time and that's why it's a voluntary thing, but of course no one in their right mind is gonna do that.

It's not just necessarily libraries its things like how to write citations. They come in to [library name] with absolutely no clue.

Some participants thought this could be used as an opportunity to help students:

It's a culture thing too, the person moaning about that you could turn it round the other way and say well they didn't come to the sessions why are we not looking for the teachable moment somewhere else like while they're in front of us show them something then.

Because then you can say to them look I'll just quickly show you they actually do run a more in-depth training session on this if you want to know more, reel them in a bit.

\subsubsection{Rising Expectations}

Customer expectations were thought to be rising and customers did not always know what they wanted: 
The more we give them the more they want.

They want it all done in five minutes.

Well we get a lot of students that come in with their assignments and they tell us what their assignment is and they stand there waiting.

Waiting for it to be completed by someone else and not them.

Customers did not always know what they wanted and participants thought that the reference interview was the way to find out and help the customer clarify their request.

Participants felt that customers expected to encounter a certain type of performance. Customers were thought to want knowledgeable service:

the information you'd provided is all rubbish but um may be that's it short term long term type thing, if you can fudge it quickly then they're never going to know until it screws up later on down the path, then they may come back because they're not happy and that may make the profession look worse long term so.

On the one hand they think you're sitting there stamping books, on the other hand they think you know all about everything and probably people think both views simultaneously which I always thought was quite strange.

You can talk and you can be on the reference desk and you can talk with confidence and the person that you're talking to thinks 'oh she knows the 
answer, and you're just making it up. You've got no idea but you're talking

with authority and sounding like you know what you're talking about...

You can actually bluff your way through you know.

I think in my experience people that come into a library have high

expectations and they assume that the person on the reference desk is going to be able to help them.

\subsubsection{Staff Culture}

It was agreed staff relationships contributed to the library culture:

And if a staff member mentions that to the other staff member instead of whinging then actually then you're developing a different culture.

It was suggested that 'good' staff could model behaviour for 'bad' staff but it was felt this would only work for certain personality types:

Yeah some of that comes back to personality types and things like that because it's the glass half empty or the glass half full. You can see it in the negative and then you just propagate that to everyone around you, or if you see it in the positive with a positive spin.

\subsection{What the Retail Model Means to Librarians and how it Compares to the Traditional Library Service Ethic.}

\subsubsection{Retail Model}

The retail model of service meant three things for the focus groups: 
1 The layout and design of the library. One person mentioned for example large chairs where people sit as being directly borrowed from the retail model

2 The exchange of money and selling.

3 Customer service:

I've worked in retail and it means things like um you acknowledge the customer in the first twenty seconds that they walk into the shop and um you don't ask them closed questions, you ask them open questions.

Generally it was felt that libraries could be customer led in the same way as retail outlets, to a degree. There was a great deal of discussion in all focus groups as to the degree. The retail model was said to fall down when libraries were run like businesses by non librarians or other entities such as councils because the focus was on the monetary side. The information environment was seen as more complex:

There isn't the one size fits all and that's the other problem with the retail model, McDonald's kind of you know well everyone has a burger and fries and a drink and that's it.

There was general acceptance of the term customer. Only two participants felt that this term was associated with retail and money.

\subsubsection{Retail Focus}

The retail model was thought to have adversely affected libraries because the concerns were focused on getting numbers through the door, repeat customers and participants made disparaging comments like ...do you want chick lit with that? 


\subsubsection{Different Values}

Education was thought to be a big part of library work:

...the education side of it, the how to use the library you probably don't expect someone in a shop to teach you how to shop.

The retail model was said to have affected the standard of service in libraries, as one person stated:

The problems I've seen in my experience in [City name] is the diminishing of that traditional reference service and what is essentially unqualified staff sitting in a position of authority and when customers are coming through they're asking difficult questions that these young eighteen year olds can't answer because they've been given a training prompt and there's diminishing of the service in respect to the education we're supposed to provide.

\subsubsection{Other Retail Outlets}

When discussing other retail outlets participants mentioned a number of retail outlets where they expected to, or had received bad service. These outlets included Dick Smiths, The Warehouse, banks and burger outlets.

When I went to get a mortgage I went to four different banks and the one that was actually the cheapest had the worst service. I had this young guy who made it clear he could barely be bothered explaining it to me. He probably lost a customer on the strength of that. I'm not going to go back to somebody that treats you like that. You can't afford to let somebody stay like that. 
I'd never dream of asking anyone in The Warehouse anything, because they just don't know their stock, they've got no idea and just wouldn't even bother asking, but if I went into a library I would always expect the person to be able to help me with something.

Places like Dick Smith, you, I had this boyfriend once and he was building some robot and he wanted a piece and he had the bit that went in the other end and he asked them for the bit and they said I don't know we don't have it what is it? He knew more about their stock than they did and that's always put me off Dick Smith the 14 year old spotty Eric's who don't know (...).

\subsubsection{Survival}

There was acknowledgement that the retail model was more important in the library world as funding depended on it. A number of participants used the word survival; that libraries need to market themselves for their future survival.

\subsubsection{Difference in Ethics}

The library professional service ethic was seen as being very different from the retail service ethic. Retail was associated with words like financial, profit, and money. Library work was described using the words professional, value, complex, education and helping people. One person said we are not cookie cutters.

\subsubsection{McDonald's}

The idea of installing a retail based training model offered by an organisation such as McDonald's was viewed very negatively. Participants felt there would be no intellectual content they would feel undervalued and ...that librarians would be very insulted. One person said: 
I think it's just the emotional reaction to being compared to someone who works at McDonald's.

Another said:

...if we were just there to sell fries then we could go and do that. Why would we work in a library?

\subsubsection{KiwiHost}

Several participants mentioned KiwiHost as a better alternative to the McDonald's model as it was less American. One person said:

KiwiHost teaches the same structure as McDonald's but in different ways.

Another said:

I've heard good and bad things about KiwiHost actually. I've heard people come back and say we didn't learn anything that we didn't know already that we're not already doing as professional librarians on the desk.

\subsubsection{Scripted Service}

The reaction to the idea of a scripted service encounter was as strong as the reaction to a McDonald's style training programme. Scripted encounters were said to be fake, robotic, demeaning, horrible, and awful. An alternative to scripted encounters was discussed by all focus groups. It was felt if the guidelines were general and not too pushy, perhaps a list of useful tips would be acceptable.

...I don't think you should be told you must...I think it could be done in a way that is not too directive. 
It depends how pushy it was if it's just a matter of saying look up, make eye contact with the customer and smile and say hello or something most of us would probably cope with that but if it got much more scripted than that.

One of the reasons against a scripted encounter was because it was felt there is never one answer to an enquiry.

Libraries were compared to retail in a negative way:

...if you turn into a good morning what can I do for you today blah blah. I mean it's just like they can go somewhere else for that, they can go to a bookshop.

When asked how other staff members would cope it was thought they would not cope and would not do it.

Overall the main theme that came through in terms of scripted service is that an occasional reminder or some loose guidelines may be acceptable but overall librarians felt they were professional enough to monitor their own behaviour:

We just do naturally.

I think we like to feel that we are professional enough to monitor our own behaviour (Yes-Agreement from others).

And judge the situation.

And not be told what to do and how we have to behave. 


\subsubsection{Emotional Script}

These comments were similar to the comments on enforced smiling. Focus groups had the same reaction to the idea of an emotional script.

Enthusiastic sets my teeth on edge.

Well if it's genuine but if somebody asked you for a book and you were like 'oh would you like this one.'

One of the reasons against an emotional script was because it was not seen as being genuine. It was felt that it would be hard to be genuine ... if you've got in the script you know, sound enthusiastic at this point.

\subsection{The Impression Librarians Aspire to Attain and how this Relates to} Status.

During the focus group participants were read the following quotes from Quotes from: Quinn (2005).

\section{Quote 1}

The librarian, who is sitting behind the service desk, slouching in a chair playing solitaire on the computer, will suddenly jump to attention, switch screens to a more professional address, or shuffle some memos, and skim them for details. (Quinn, 2005, P. 339).

\section{Quote 2}

The academic librarian who wishes to maintain an impression of being cerebral and erudite will be careful not to bring her copy of Soap Opera Digest to the reference desk to peruse between transactions. Instead, a copy of the latest issue of the Times Literary Supplement or the New York Review of Books...' (Quinn, 2005, p. 334). 
The first quote about solitaire caused knowing laughter from all focus groups; some participants admitted playing solitaire or other games during desk duty and quickly switching screens when others were about. If your manager's coming you quickly flick your information to the right page. Playing solitaire was not thought to give a good impression because the work environment was open and people could see what you were doing. Also solitaire was not work and people should be working when they are on the reference desk:

There are plenty of other things you could be doing with your time.

You could do shelving or putting things on display.

One librarian said she had seen a librarian in a public library playing solitaire and had rung the library to complain.

Participants discussed the reasons for not wanting to give the impression of not working:

I think it can be a personal thing too sometimes taking your work down on the front desk isn't the thing to do sometimes so therefore you'll distract yourself and go do some shelf checking, then you'll think, na, I've had a crappy day, I'm just going to sit here and read emails. But yeah I think it's all about how other people will interpret me, if I'm sitting there slouching.

You want to look as if you're doing the right thing even though you mightn't be doing the right thing.

I think if you've got nothing else to do. 
I mean it's probably a mixture of perception management, camouflage and actually having some other stuff to do because there's not much to do at the desk.

Participants also laughed at the second quote admitting this also happens. Participants pointed out that this type of impression management occurs in all professions:

I don't think it's peculiar to libraries. I think that would happen in lots of work situations. People would be doing things for personal interest or the things that they are doing don't look intellectual enough for the environment I reckon.

I think it's normal, I think it's just normal work practice really.

One focus group suggested it was designed to give the impression that librarians were more intelligent. One person said in a joking way: Well that's probably true. Another participant thought it was elitist.

Two participants thought it was important to create an impression of intelligence:

...in an academic library you've got students coming in who think they are the bees knees that they know everything and they're just there just to get their piece of paper and move on, and so if you turn up and you're sitting there with your wee soap thing that I would read everyday um they will go 'oh well they're not really that intelligent then are they? How are they going to be able to help me?' So on the other side to that as well there needs to be that sort of sense of professionalism as in you know like in this person might actually know what they're talking about so... 
I take a copy of the New Scientist on the reference desk. I wouldn't necessarily always read that sort of material it's because with our students there's this perception sometimes that they, they don't actually realise that the person behind the desk counter might have a Masters in that area they're like oh I'm doing a degree (Mmm, yes), I'm already better then you. Because their perception is the other again of you being retail (yeah) And I like to challenge that impression because for me to provide a good reference service for them they need them to think I can actually provide them with information that they don't know how to source.

The idea of creating a less cerebral impression was also discussed:

Oh it is, it's not it's not welcoming once again to the person coming up to the desk because if they are someone who perhaps hasn't had a lot of education and they see that they're going to be quite intimidated I think.

It's the same experience in the retail thing because if you go into a shop and this is going to sound terribly ageist but you have all these young people in their looking really cool with their sunglasses on and you feel quite uncomfortable about going in and out to look at something because they're not really that interested in you, you're old and again it's sort of the same sort of thing but in reverse it's the retail industry as well.

When they saw our stash of Women's Days they said oh my God you have this stuff. And so on a plus side it develops a bit of a relationship for that lower end stuff. 
The reasons for creating a good impression, even if you were pretending to work were thought to be because librarianship was misunderstood. One person said it was because the impression is that people who work in libraries are intelligent but not busy.

You want to be seen as a professional.

Or that you are busy.

Or that you are a serious person doing something serious.

The unfortunate thing is a lot of people see librarians as putting books on the shelves and issuing books and that's it.

I wonder if a lot of it comes down to the nature that again as I said earlier that the libraries tend not to be run by librarians and they're run by people who don't understand the work, the industry and quite frankly have no real value in library so it's a perception management thing. You don't want one of those managers to waltz, a councillor would be a good example, to waltz in known to be anti library and see you sitting there with a noisy boom or just sitting there sitting there not doing anything.

\section{Analysis}

Goffman (1959) says the beliefs and values of a particular social group have a direct effect on behaviour. These beliefs and values are learned backstage during every day social interactions and conversations. Individuals learn from each other what is embedded in the culture (Wager, 2007). In a workplace individuals learn the 
“...norms of a profession” (Wager, 2007, p. 638). Backstage is where the actors learn how to perform and this learning that takes place backstage influences the service culture. This study explores backstage learning, focusing on the connection between backstage attitudes and front-stage behaviour.

There was general acceptance and awareness of the importance of looking friendly and approachable during a service encounter, but interestingly librarians in this study saw themselves as capable of behaving in an appropriate manner without being told how to. Participants expressed opposition to the idea of any kind of enforcement. Being told how to smile was seen as belittling and unnecessary. Any attempt to standardise or script the process of service delivery was viewed as demeaning and robotic.

Other studies have acknowledged that librarians are resistant to the implementation of service programmes (Bishop \& Bauer, 2002; Paul, 1990; St Clair, 1993). It is an insult to their intelligence and professionalism to be trained to smile (Fox, 2005; Siess, 2003; Walters 1994). Librarians have expressed antagonism to customer service programmes (Deane, 2003; Paul, 1990). "There is a tendency to characterize it as 'what Wal-Mart does,' as if employees that make sure that they look at you, speak to you, smile at you, help you, and thank you is a bad thing" (Deane, 2003, p. 317).

Sturdy (2001) adds further insight into service behaviour which may help to explain librarian resistance to enforcement. Sturdy argues that society's move to the standardised service encounter has created a loss in authenticity. The 'have a nice day' message is now commonly perceived as being 'fatuous' and 'empty' (Sturdy quoting Finklestein, 2001, p. 8). Participants expressed annoyance at customer service in retail. They did not like the overzealousness of shop assistants ...in shops when you 
get two or three people asking you if you need anything... Korcynski (2001, p. 80) describes contemporary service work as 'fake', 'invasive' and 'demeaning.' Participants in this study also used the word fake to describe how they felt about the idea of enforcement in service.

Goffman (1959) suggests that routine aspects of occupations are downplayed in favour of spontaneous aspects. "By maintaining a degree of social distance, performers appear more mysterious and idealized to their audience (Quinn, 2005, p.336). It could therefore be said that librarians idealise spontaneous unforced service behaviour. The routinisation of the service encounter lacks spontaneity which is thought essential in libraries because libraries are offering a more complex experience. Some people need 20 seconds some people need two hours...we are not cookie cutters. This reaction to service is in line with the attitude to the implementation of the business model into librarianship. Rubin (2004) notes that libraries and businesses have different purposes. The profit driven business model was not viewed as appropriate for libraries.

Traditionally library staff were recruited because of their process oriented skills and interest in the product (McArthur \& Nicholson, 2005). It is now an expectation for librarians to be people oriented and have good interpersonal skills. Not only is it difficult to change an organisations traditional front, what makes this situation more complex is that the concept of placing the customer at the centre of service has arisen from the business model. This does not sit comfortably with the traditional library service ethic as one participant makes the point ...previously we concentrated quite thoroughly on the reference interview...but once we implemented the retail service 
model it was more about getting numbers through the door, and about getting those circulation statistics up.

Parallels can be drawn between the car sales team in Wager's (2007) study and librarians in the current study. The car service advisors, like librarians thought more in terms of knowledge than actual customer service. The interest in customer service was secondary. Both librarians and service advisors saw themselves behaving in a neutral and objective way, to maintain some distance. A service advisor in Wager's study said we aren't psychologists. We are engineers and technicians (Wager, 2007, p. 643). A librarian in the current study said you want to be seen as professional.

"An organisation no matter how poor they are at customer service, can get it right some of the time, but great service requires getting it right all of the time"(McArthur \& Nicholson, 2005, p. 2). It is clear from this current study that there are librarians working with the public who are known to deliver poor service. Although the librarians who attended the focus group sessions thought of themselves as comfortable delivering a good customer service performance, there were librarians who were seen as incapable of performing well. 'I think you've either got it or you don't.' 'You either like people or you don't'. 'It can be difficult for shy introverted people.' The idea that service delivery is dependent on whether you like people is interesting. It implies that if you are not a people person you cannot deliver good service and cannot be trained in customer service. McArthur \& Nicholson (2005, p. 2) claim that librarians make excuses for the delivery of poor service. The librarians in this study did not make excuses for themselves but for the 'other' librarians. McArthur \& Nicholson say that it is hard to find any other organisation other than libraries that takes so little responsibility for the delivery of service. 
A service advisor in Wager's (2007) study said he was aware that people wanted friendly service, though he did not always have the energy to deliver it. Though in his last job he professed to consistently delivering good service because the company was “extremely service minded" (p. 646). Wager suggests the backstage learning in his last job was more constructive, which raises the question does the attitude and behaviour of a group more strongly influence the behaviour of an individual than the innate ability of that person? Goffman (1959) argues that a sense of commonality develops in a group that has little relationship to an individual's personality.

Goffman (1959) says that people who do not meet the required performance standards tend to be dropped from the performance. Bad performers in libraries seem to maintain their part in the act. One participant discussed hypothetically what she would do if she encountered a colleague delivering bad service: Unless you stepped in and said can I help and actually took over from them and kind of tried to politely get the person out to the back rooms. I think it's possible to do that, step in and say oh I'm here to relieve you I'll take this. The rest of the group all agreed with this and one said ...just kind of subtlety. Teams are dependent on each other and Goffman calls shattering such illusions as unmasking. Thus it could be argued that this behaviour is an acceptable part of the performance as it is not being dealt with in a direct way and therefore it is likely to continue. The librarians who deliver bad service are never unmasked, which only serves to perpetuate the behaviour.

Research has also shown that librarians who deliver bad service are just as likely to believe they are delivering good service as the librarians who do in fact deliver good service (Fox, 2005). So how do libraries identify which staff are strong at service delivery and which staff are poor? According to the participants in this study customer 
service behaviour is not monitored or enforced. This implies that service behaviour is left up to the discretion of the individual staff member. Or are staff ignoring the service rules? Participants did acknowledge that they would show resistance to service behaviour that was deemed demeaning or enforced; this suggests the latter is possible.

Recruitment policies are one of the main instruments libraries use to change their culture. Participants were generally positive about the idea of advertising for interpersonal skills as a way of changing the culture. It was acknowledged that it was very difficult to get rid of people once they were in the job. This backs up Goffman's theory that even if the desire is there, it is almost impossible to change a well established front. The desire for groups to keep the show going overrides the desire to reveal weaknesses to their audience. Other attempts to change the culture were thought to be unsuccessful as some participants felt library schools were failing in their attempt to recruit people with interpersonal skills. And you still see students coming out who are drongos (laugh) and they're hiring them.

Although there was clearly a strong desire by all participants to change the culture of libraries to one with friendly and approachable staff the idea of employing staff without knowledge and education was seen as aligned with the retail model, and was viewed very negatively. Quinn's (2005) claims that the major problem in libraries is that education and experience is downplayed in favour of interpersonal skills reveals the deep fear held by many in the library community, that somehow by embracing values from retail librarians will be selling out. This attitude was still prevalent amongst participants who saw non-professionals as a threat.

Participants did see the face-to-face service encounter as a performance and even felt they could fake friendliness. This may seem contradictory but it was clear that this 
behaviour was chosen and not enforced. It was still viewed as something that could be done naturally to serve a purpose. An actor giving a performance may see the performance as sincere and genuine or they may be cynical and believe their performance is a means to an end (Goffman, 1959). When participants discussed the implementation of the retail model and what it would mean to the service encounter the following comments were made....do you want chick lit with that as well? Would you like to upsize your book with that? It was interesting how many participants used fake voices to emphasise the behaviour that they believed would infiltrate libraries if the retail model was allowed to take hold. Librarians would be cynical about this type of performance but the performance that they perform as actors is one they believe is sincere. As one participant said it's not easy to be sort of fakely enthusiastic.

Goffman (1959) argues that whether conscious or not a performer will always convey an impression to an audience that meets the needs of the performer emphasising the behaviour “...from which his occupational reputation derives” (Goffman, 1959, p. 33). Librarianship continues to value education, knowledge and traditional reference services. Fox (2005) suggests librarians place a high value on knowledge during a service encounter. The retail model was seen to place little value on knowledge and education as one participant said ...essentially unqualified staff sitting in a position of authority and when customers are coming through they're asking difficult questions that these young eighteen year olds can't answer because they've been given a training prompt and there's diminishing of the service in respect to the education we're supposed to provide. It was clear that the desired act needed to include the impression that the performer possessed knowledge and intelligence whilst acting sincerely. It was perceived as important that a librarian knew what they were talking about. 
Quinn also reveals another major fear in librarianship, and that is librarians are becoming crowd pleasers to their audience. "Style takes precedence over substance in a culture in which impressions are critical" (Quinn, 2005, p. 349). The flaw in this analysis is that one is always giving an impression whether consciously or not. Individuals collaborate to stage the desired routine that conveys the impression they want to convey whether they are aware of this or not (Goffman, 1959; Wager, 2007).

Quinn (2005) expressed concern that too many decisions in libraries were now made with the customer in mind. Customers do not always know what they want and placing them at the centre of an organisation is a mistake, because it is impossible to keep them constantly satisfied and the goal posts are constantly moving. Participants in this study did feel that customers can expect too much and expressed resistance to the role of crowd pleaser. Therefore it could be argued that librarians are expressing resistance to customers, as their audience members, taking centre stage.

Because participants saw themselves as more professional than retail they also tended to perceive that their audience required a certain impression. As one participant said there's an expectation that there is some education behind the person that's serving in the library... A stereotype of retail emerged during the sessions. As another participants said I'd never dream of asking anyone in the Warehouse anything, because they just don't know their stock, they've got no idea and just wouldn't even bother asking, but if I went into a library I would always expect the person to be able to help me with something. Other comments by participants expressed a similar attitude that retail outlets often had untrained staff with no knowledge or inclination to be helpful. The fear seems to be that this style of service is creeping into libraries and participants felt that this is not what their audience wants. Hernon, Nitecki and 
Altman (1999) say that librarians hold onto the belief that they already know what customers want and need.

The idea that a librarian knows what the audience wants affects their performance. In any given performance the actors under-communicate some aspects and overcommunicate others (Goffman, 1959). Thus librarians over-communicate knowledge and expertise as these are highly valued, but they under-communicate a welcoming demeanour when the public enter the library. Goffman suggests people “...invest their egos into certain routines giving less stress to others. There was a strong reaction to the idea of being associated more closely with retail than other more professional bodies.

Another important perception was that librarians thought their audience saw them as being intelligent but not busy. Consequently librarians should look busy at the service desk.

It's a balancing act though because most of us are working at something while we're waiting to be asked... instead of sitting there doing nothing than staring at the customers, it'll probably make them nervous...

This idea of being seen to be working while on the desk was very entrenched. One participant said that at one library she had worked in they were not allowed to do any work on the desk at all, so they could look available to people. This was considered by the other participants to be unproductive. This participant said it was boring and I'd go off and straighten shelves not too far from the desk or do other things to occupy my time, generally tidying. Looking available was not as important as looking busy. McArthur and Nicholson (2005) note that some librarians have been found to be so 
focused on shelving and tidying that they are unaware of customers and what is happening around them.

Quinn (2005) discusses the dramaturgical term 'make work.' "This involves the impression that one is busy, working hard trying to accomplish as much as possible, whether or not this is actually the case. 'Make work' is especially likely to be engaged in when certain audience members are present, particularly those in a supervisory role" (Quinn, 2005, p. 339).

This study has shown that 'Make work' is very much part of the performance repertoire in libraries. It is seen as something expected by customers. This view does not concur with current research, as Chelton (1999) points out "Library practitioners would do well to note that users remember more how they are treated in a service encounter than what they got from it" (p. 109). The current study shows librarians are holding on to the perception that they need to act knowledgeable, busy and wait to be approached you don't want to go chasing them. This attitude of not being pushy or chasing customers and looking busy could give the impression of disinterest.

\section{Summary}

This study found that the learning that is taking place backstage in libraries is influencing service behaviour.

The library was seen to offer a better level of service than retail. Customers were thought to want to encounter a knowledgeable library staff member. This framing of customer expectations reflects the traditional library service ethic, which is steeped in values that place librarians in a high status role as guardians of knowledge for the betterment of the individual and the advancement of civilisation (Gorman, 2003; 
Rubin, 2004). This traditional ethic is precisely what separates librarianship from retail. The retail model is seen to be distorting the service ethic of the library profession (Rubin, 2004). The retail ethic is profit driven and therefore has no concern for the needs of the individual and society (Black \& Crann, 2002).

As Wager (2007) found, membership in the group culture helps shape the desire to behave in a certain way. The culture of the group is stronger than the individual's desire to behave in a certain way. This is not always constructive learning. "...members of a community can learn to think and behave in ways that can diminish a service culture and ultimately, service quality... The learning that takes place backstage can influence the service culture negatively (Wager, 2007). The backstage learning amongst librarians suggests that librarians are not placing a high value on customer service training as the view is it is not a complex process.

Although there was an acceptance one could learn from the retail model there was a great deal of commonality expressed by participants in their criticisms of retail. Negative stories of inexperienced staff that neither cared nor knew how to deliver good service were shared. Points of difference were emphasised and stories of the dangers of the infiltration of this model into library practice were shared.

Quinn (2005) implies that there is a collision between the two service models. A library job was seen as a lot more complex than getting your burger and taking money. What seems to be made clear from this study is that librarians have two completely different definitions of service. There is the library service ethic and the retail service ethic. 
The traditional service attitude of librarians seems so deeply entrenched. McArthur \& Nicholson (2005) argue that librarians need to change their mindset and stop clinging to the belief that knowledge and information is their main function when people are their main function.

The retail model would undervalue the work of a librarian. If we were just there to sell fries then we could go and do that, why would we work in a library? Similar comments were made in other studies. "Why not go to the McDonalds University or work in a Wal-Mart if you want to learn how to provide service?" (Miranda-Murillo, 2004, p. 41). Goffman (1959) would see this as resistance. A group tries to be seen in the light it wants to be seen in. It is clear that librarians in this study do not want to be seen as shop assistants.

"To just live in the world of values or disassociated measures can lead to illusions of value to users. Worse, it can lead to complacency, smugness, and resistance to the kind of disruptive change that is needed (Deane, 2003, 319)."

Would you like to upsize your book with that? (Yeah, laughter) 


\section{Bibliography}

ALA policy manual: ALA handbook of organization. (2007). Retrieved October 31, 2007, from American Library Association Web site:

http://www.ala.org/ala/ourassociation/governingdocs/policymanual/policyman ual.31_3.pdf.

Bishop, K., \& Bauer, P. (2002). Attracting young adults to public libraries: Frances Henne/YALSA/VOYA research grant results. Journal of Youth Services in Libraries, 15(2), 36-44.

Black, A., \& Crann, M. (2002). In the public eye: a mass observation of the public library. Journal of Librarianship and Information Science, 34(3), 145-157.

Calvert, P. (2000). International variations in measuring customer expectations.

Paper presented at the ARL Measuring Service Quality Symposium, Washington D.C.

Calvert, P. (2005). It's a mystery: mystery shopping in New Zealand's public libraries. Library Review, 54(1/2), 24-35.

Calvert, P. (2001). Scholarly misconduct and misinformation on the World Wide Web. The Electronic Library, 19(4), 232-240.

Catterall, M., \& Maclaren, P. (1997). Focus group data and qualitative analysis programs: coding the moving picture as well as the snapshots. Sociological Research Online, 2(1). Retrieved January 19, 2008 from: http:www.socresonline.org.uk/ socresonline/2/1/6.html.

Chelton, M. K. (1999). Behavior of librarians in school and public libraries with adolescents: implications for practice and LIS education. Journal of education for library and information science, 40(2), 99-111. 
Chelton, M. K. (1997). The 'overdue kid': a face-to-face library service encounter as Ritual Interaction. Library \& Information Science Research, 19(4), 387-399.

Cullen, R. (1999). Does performance measurement improve organisational effectiveness? A postmodern analysis. Performance Measurement and Metrics Sample Issue, 9-30.

Deane, G. (2003). Bridging the values gap: getting past professional values to customer value in the public library. Public Libraries, 42(5), 315-319.

Fisk, R. (1996). Applications of impression management and the drama metaphor in marketing: an introduction. European Journal of Marketing, 30(9), 6-12.

Foskett, D. J. (1962 Reprint 1970). The Creed of a librarian: no politics, no religion, no morals. London: The Library Association.

Fox, H. (2005). An investigation into political and professional attitudes regarding commercialised models of service provision in public libraries.

The University of Sheffield: Sheffield.

Goffman, E. (1959). The Presentation of self in everyday life. New York: Doubleday Anchor Books.

Goldman, A., \& McDonald, S. (1987). The Group depth interview: Principles and practice. New Jersey: Prentice-Hall INC.

Gordon, W., \& Langmaid, R. (1988). Qualitative market research: a practitioner's and buyer's guide. Aldershot: Gower Publishing Company.

Gorman, G. E., \& Clayton, P C. (1998). Qualitative research for the information professional a practical handbook. London: Library Association Publishing.

Gorman, M. (2003). The Enduring library: technology, tradition, and the quest for balance. Chicago: American Library Association. 
Goulding, A. (1997). Joking, being aggressive and shutting people up: The use of focus groups in LIS research. Education for Information, 15(4).

Greenbaum, T. (1988). The Handbook for focus group research. New York: Lexington Books.

Grove, S J., \& Fisk, R P. (1983). The dramaturgy of service exchange: an analytical framework for service marketing In L.L. Berry, Shostack, G.L. and Upah, G.D. (Eds), Emerging perspectives of service marketing. American Marketing Association: Chicago, IL.

Guba, E., \& Lincoln, Y. (1981). Effective evaluation. San Francisco: Jossey-Bass Publishers.

Hauptman, R. (2002). Ethics and librarianship. North Carolina: McFarland. Hernon, P., Nitecki, D A., \& Altman, E. (1999). Service quality and customer satisfaction: an assessment and future directions. Journal of Academic Librarianship, 25(1), 9-17.

Hood, D., \& Henderson, K. (2005). Branding in the United Kingdom public library service. New Library World, 106(1/2), 16-28.

John, J. (1996). A dramaturgical view of the health care service encounter. European Journal of Marketing, 30(9), 60-74.

Johnstone, K (1981). Impro: improvisation and the theatre. London: Methuen.

Kitzinger, J. (1994). The methodology of focus groups: The importance of interaction between research participants. Sociology of Health \& Illness, 16(1), 103-121.

Koehler, W. (2003). Professional values and ethics as defined by 'the LIS discipline'. Journal of Education for Library and Information Science, 44(2), 99-113.

Koontz, C. (2002). Stores and libraries: both serve customers! Marketing Library Services, 16(1). 
Korcynski, M. (2001). The contradiction of service work: call centre as customeroriented bureaucracy. In A. Sturdy, Grugulis, I., \& Willmot, H (Ed.), Customer service: Empowerment and entrapment. New York: Palgrave.

Kruegar, R. (1994). Focus groups: a practical guide for applied research. California: Sage.

Langford, J., \& McDonagh, D. (2003). Focus groups: supporting effective product development. London \& New York: Taylor \& Francis.

Leedy, P., et al. (1997). Practical research: Planning and design. New Jersey: Prentice-Hall Inc.

Massey-Burzio, V. (1998). From the other side of the reference desk: a focus group study. The Journal of Academic Librarianship 24(3), 208-215.

McArthur, M., \& Nicholson, K. (2005). The customer care challenge. Public Library Journal, 20(2), 2-4.

McNichol, S. (2004). Investigating non-use of libraries in the UK using the massobservation archive. Journal of Librarianship and Information Science 36(2), 79-87.

Melling, M. L. J. (2002). Building a successful customer-service culture: a guide for library and information managers. London: Facet Publishing.

Meyers, E. (1999). The Coolness factor: ten libraries listen to teens. American Libraries, 30(10), 42-45.

Miao, M., \& Bassham, W B. (2007). Embracing customer service in libraries. Library Management 28(1/2), 53 - 61

Miranda-Murillo, D. (2004). The value of service in the library and information science curriculum., University of Texas: Austin. 
Mitchell, J. N. (1978). Social exchange, dramaturgy and ethnomethodology: toward a paradigmatic synthesis. New York: Elsevier.

Morgan, D. L. (1988). Focus groups as qualitative research (Vol. 16). California: Sage.

Muir, L. (2001). Where now for the UK public library service? Library Management, 22(6/7), 266-271

O'Connell Davidson, J., \& Layder, D. (1994). The research process: theory and evidence. In Methods, sex and madness (pp. 41-49). London: Routledge.

Owen, C. (1998). What do teenagers really want? Investigating both sides of young adult services. Victoria University: Wellington.

Panteli, N., \& Duncan, E. (2004). Trust and temporary virtual teams: Alternative explanations and dramaturgical relationships. Information Technology \& People, 17(4), 423-441.

Patton, M. Q. (1987). How to use qualitative methods in evaluation. California: Sage Publications Inc.

Paul, M. (1990). Improving service provisions. The Australian Library Journal, Feb(39), 64-69.

Pickard, A. L. (2007). Research methods in information. London: Facet publishing.

Quinn, B. (2005). A dramaturgical perspective on academic libraries. Libraries and the Academy, 5(3), 329-352

Ranganathan, S. R. (1963). The five laws of library science. Bombay: Asia Publishing House.

Rodger, J. (1998). Core values: Our common ground. American Libraries, 29(9), 6871. 
Rubin, R. (2004). Foundations of library and information science. New York: NealSchuman.

Sandy, J. (1997). By any other name, they're still our customers. American Libraries, 28(7), 43-46.

Shontz, M., Parker, J., \& Parker, R. (2004). What do librarians think about marketing? A survey of public librarians' attitude The Library Quarterly, 74(1), 63-84.

Siess, J. A. (2003). The visible librarian: Asserting your value with marketing and advocacy. Chicago: American Library Association.

St Clair, G. (1993). Customer service in the information environment. London: Bowker-Saur.

St. Lifer, E. (2001). What public libraries must do to survive. Norman Library Journal, 126(6).

Stewart, D., \& Shamadasani, P. (1990). Focus groups: theory and practice. California: Sage.

Strauss, A. L. (1987). Qualitative analysis for social scientists. Cambridge: Cambridge University Press.

Sturdy, A. (2001). Servicing societies? -Colonisation, control, contradiction and contestation. In A. Sturdy, Grugulis, I., Willmot, H (Ed.), Customer service: Empowerment and entrapment (pp. 1-18). New York: Palgrave.

Sturdy, A., \& Fineman, S. (2001). Struggles for the control of affect-resistance as politics and emotion. In A. Sturdy, Grugulis, I \& Willmott, H (Ed.), Customer service: Empowerment and entrapment (pp.135-156). New York: Palgrave.

Todaro, J., \& Smith, M. (2006). Training library staff and volunteers to provide extraordinary customer service. New York: Neal-Schuman. 
Urban libraries council PLPYD Youth Voice. (2001). Retrieved July 27, 2007 from: http://www.urbanlibraries.org/plpyd/giveback1.html.

Wager, K. (2007). Learning in a service context: going backstage. Managing Service Quality 17(6), 635 - 655.

Walker, L. (2007). Integrating public libraries and council customer service centres: The South Taranaki library plus. Australian public libraries and information services 20(1).

Walter, V., \& Meyers, E. (2003). Teens and libraries: getting it right. Chicago: American Library Association.

Walters, S. (1994). Customer service: A how-to-do-it manual for librarians. New York, London: Neal-Schuman Publishers, INC.

Weingand, D. E. (1997). Customer service excellence: a concise guide. Chicago: American Library Association. 


\section{Appendix}

\section{Appendix A: Information Sheet and Consent Form}

Date

Name

Dear [Name],

Thank you for giving up your time and agreeing to participate in a focus group session.

The purpose of this research is to investigate the attitude of librarians to service. The research findings will help shed light on the issues surrounding customer care in libraries.

The research data will be deposited in the Victoria University Library and data may also be used for conference papers and journal articles.

The study is being undertaken by Jane Cherry, who is currently completing The Master of Library and Information Studies (MLIS) at Victoria University of Wellington. The project is supervised by Philip Calvert, Senior Lecturer in the School of Information Management.

The focus group interviews will last approximately 45 minutes. A sound recording will be made of each focus group. The researcher will take field notes during the sessions. Please be reassured that the information you provide will be treated confidentially. The tape recordings, focus group transcripts, and field notes will only be used for the current research project. The researcher will keep all notes and materials relating to the research in a secure and locked location. These materials will be disposed of within one year of the completion of the research project.

Participation in this study is voluntary. Participants can withdraw from the focus group up to the time the focus group session begins. After this point withdrawing will not be an option as it is hard to separate out contributions from individual participants during a group discussion. Participants can refuse to answer any questions or be involved in any discussions. If you have any questions or queries do not hesitate to contact me:

Jane Cherry

Home:[Phone number]

Work: [Phone number]

Email: [Address] 
Please take a moment to read the following conditions:

I have been given information on the nature and objectives of the research and I have been given the opportunity to seek further clarification from the researcher.

I understand that after the focus group session begins I will not be able to withdraw as participant's contributions are hard to separate out from each other and my contribution may influence other contributions.

I understand that I may opt out of joining any discussion or answering any questions during the focus group sessions.

I understand that if I do withdraw from the project my name and contact details will be immediately destroyed.

I agree not to disclose what is said during the sessions to protect the confidentiality of other participants.

I understand that the research will be deposited in the Victoria University Library and may also be used for journal articles and conference papers. If the researcher uses any research material for any other purpose I will be asked to supply formal consent.

I understand that all transcripts and other related material will be destroyed one year after the completion of the research project.

I have read and understand the above information, and agree to participate in this study.

$\overline{\text { (print name) }} \overline{\text { (signature) }}$

Participant

(print name)

(signature)

(date)

Researcher 


\section{Appendix B: Focus Group Guide}

Please note prompt questions will only be asked if content is not covered.

Discussion

Do you think it is important to be interested in people to become a librarian?

\section{Prompts}

How would you feel about being required to provide a smile?

Do you think people can fake friendliness?

Do you think it is realistic for every customer to get the same service?

If you have been involved in customer service training what did you think of it?

Is it realistic to treat every customer as you would a friend?

Can you be too friendly with a customer?

Discussion

Customer, client, patron, user are all words used in libraries. Do you have any thoughts or associations with any of these terms?

\section{Discussion}

What does the retail model of customer service mean to you?

\section{Prompts}

Can libraries be customer-led in the same way as retail outlets?

How do you think the retail model has affected libraries?

Are there differences between the library professional service ethic and retail service ethic?

\section{Discussion}

If your library installed a retail-based training programme offered by an external organisation such as McDonald's what do you think would happen?

\section{Prompts}

How would you feel about being required to provide a scripted service encounter? How would you feel about having to display emotions like enthusiasm if you did not feel it?

\section{Discussion}

What do you think when you see library job descriptions and advertisements with phrases like ... are you passionate about customer service? ...you'll be brimming with energy and enthusiasm...

\section{$\underline{\text { Discussion }}$}

Customer expectations are said to be constantly rising. Is that what you have found?

\section{Prompts}

Do you think customers always know what they want?

Do you ever think customers expect too much? 


\section{Discussion}

Librarians learn expected behaviour not only during a service encounter but also by interactions and conversations with other colleagues. Example "If the students are not going to bother coming in to the training sessions we offer, then we shouldn't bother helping them too much."

\section{$\underline{\text { Prompts }}$}

Do you think there is a link between the service attitude and service behaviour? If you thought a colleague was not good at delivering service would you talk to them about this? Would you talk to anyone else about your colleague?

If a customer complained that you were rude to them what would happen?

\section{Discussion}

Should librarians who are not good at service be put on the service desk with the public?

\section{$\underline{\text { Prompts }}$}

Why are they put with the public?

Do you think these librarians who give bad service would benefit from a scripted service model?

What would happen to these librarians if they worked in the retail sector?

Are librarians who give bad service reprimanded in any way or less likely to be promoted?

What do you think of the expression thinly disguised contempt?

\section{Discussion}

'The librarian, who is sitting behind the service desk, slouching in a chair playing solitaire on the computer, will suddenly jump to attention, switch screens to a more professional address, or shuffle some memos, and skim them for details' (Quinn, 2005, p. 339).

If you recognise this in your own behaviour or the behaviour of other librarians what do you think the reason is? Why does it matter if a colleague/customer sees you playing solitaire?

\section{Prompts}

(My own example: I am so concerned that people may think I am reading the paper at the service desk when I am collecting clippings that I hold the scissors to indicate that I am about to cut out articles).

\section{Prompts}

¿Some librarians may bring work to the reference desk not necessarily to do work but to convey the appearance that they are engaged in work activity. Other librarians will bring a combination of work and non-work activities, so that underneath a stack of book reviews there is a crossword puzzle in case the librarian does not feel like working.' (Quinn, 2005, p.339)

\section{$\underline{\text { Discussion }}$}

'The academic librarian who wishes to maintain an impression of being cerebral and erudite will be careful not to bring her copy of Soap Opera Digest to the reference 
desk to peruse between transactions. Instead, a copy of the latest issue of the Times Literary Supplement or the New York Review of Books...' (Quinn, 2005, p. 334). 
Word Count 15, 840 